\title{
Effect of calcium hydroxide on slip casting behaviour
}

\author{
Aylin Şakar-Deliormanlı ${ }^{\mathrm{a}, *}$, Zeliha Yayla ${ }^{\mathrm{b}}$ \\ ${ }^{a}$ Chemical Engineering Department, Izmir Institute of Technology, Gülbahçe Köyü, Urla, Izmir, Turkey \\ ${ }^{\mathrm{b}}$ Buca Education Faculty, Chemistry Department, Dokuz Eylul University, Buca, Izmir, Turkey
}

Received 1 October 2002; received in revised form 31 March 2003; accepted 22 April 2003

\begin{abstract}
The effect of calcium hydroxide addition on the casting performance of ceramic slips for sanitary ware was studied. Powder composed of feldspar (24 wt.\%), quartz (24 wt.\%), kaolin (35 wt.\%) and ball clay (17 wt.\%) was mixed with water to contain 65 wt.\% of solids (specific density $1800 \mathrm{~g} / \mathrm{l}$ ). Either $\mathrm{Ca}(\mathrm{OH})_{2}$ or $\mathrm{Na}_{2} \mathrm{CO}_{3}$ was added at concentrations ranging between 0.060 and 0.085 wt. $\%$ and the slurries were dispersed by the optimum addition of sodium silicate.

Calcium hydroxide in presence of sodium silicate improved the casting behavior of the slips, lowering the viscosity, and water absorption, increasing bending strength and cake thickness, as compared to the addition of sodium carbonate.
\end{abstract}

(C) 2003 Elsevier B.V. All rights reserved.

Keywords: Slip casting; Clays; Electrolytes; Ceramic processing

\section{Introduction}

The slip casting process is widely used to consolidate ceramic particles from aqueous suspensions. In this process a porous mould is filled with a slip, consisting of a ceramic powder mixed with water. The capillary action due to the pores in the mould withdraws the liquid medium from the slip. Excellent fluidity, low water content, high stability, and high water permeability are essential properties in ceramic slip casting (Shan, 1990).

The main factor for successful wet processing of slips that contain clay is the interactions between the particles. Chemical additions strongly affect the sur-

* Corresponding author. Tel.: +90-232-4986246; fax: +90-2324986355.

E-mail address: aylindeliormanli@iyte.edu.tr (A. Şakar-Deliormanlı). face chemistry of the ceramic powder by increasing or decreasing the interaction forces between the particles (Everest, 1988; Rosen, 1989; Reed, 1995).

The quality and strength of the final product depends on the microstructure of the cast layer. Highly porous bodies formed by a flocculated slip will usually shrink unevenly during drying and sintering, resulting in cracks and reduced strength. On the other hand a dispersed slip has less particle aggregation and better structural uniformity (Zhang and Binner, 2002).

Negative surface charge of clay particles is due to isomorphous substitution in the crystal lattice and it is neutralized by exchangeable cations. Edge charge depends on adsorption of ions, e.g. $\mathrm{OH}^{-}$ions on edges of kaolinite particles may induce a negative charge, whereas at $\mathrm{pH}<7$ it is positive and edge-toface attraction may increase the strength.

The charged surfaces of clay particles selectively attract charged ions from the solution, resulting in the 
formation of a double ionic layer on the particles. Diffuse double layer is formed by exchangeable cations due to their thermal motions. Interaction of these layers of neighboring particles (if the distance is short enough) results in diffuse double layer repulsion. In the case of small clay particles (high specific surface), highly dispersed, the viscosity may be high. This process is of fundamental importance in forming of ceramic shapes from slurries (wet forming), such as slip casting (Shan, 1990; Williams, 1992; Luckham and Rossi, 1999).

Many scientists have studied the effects of different chemical agents such as sodium tripolyphosphate, sodium polymethacrylates, ammonium phosphate, sodium citrate, polysulfonate on the dispersion behaviour of clay particles in aqueous systems (Papo et al., 2002; Guler and Balci, 1998; Corradi et al., 1994). Sodium carbonate and sodium silicate are well known deflocculants used for sanitary ware ceramic slips. Mixtures of these two chemical agents are usually the most satisfactory. Sodium hydroxide is also as active as sodium carbonate and sodium silicate, but it is not used to a great extent because of its corrosiveness (Mutsuddy, 1994).

A major disadvantage of slip casting is the time required for casting which can take from hours to days for large objects. Therefore, technologies are desired which can increase the casting rate. Methods of accelerating the consolidation of ceramic particles have been studied by many researchers (Ching et al., 1994; Zhang and Binner, 2002).

The aim of this study was to investigate the casting behaviour of clay based ceramic slips in the presence of calcium hydroxide. Effect of calcium hydroxide was studied in sanitary ware slip containing sodium silicate as dispersing agent. Similar experiments were performed with slips containing sodium carbonate and sodium silicate since these chemical agents are well known in sanitary ware slip preparation. A comparison was made to observe the differences between two systems based on casting properties.

\section{Experimental}

\subsection{Materials}

The ceramic powders used during the experiments, potassium feldspar, quartz, ball clay and kaolin, were supplied by a sanitary ware production company (Serel-Turkey). Chemical analysis of the raw materials, which was reported by the manufacturer, is given in Table 1. Chemical agents were obtained from Merck Chemicals, Germany. Distilled water was used for the suspension preparation.

Experiments were performed in two different sets. The first set of suspensions was prepared by using sodium carbonate at different concentrations ranging from 0.06 to $0.085 \mathrm{wt} \%$ and adequate amount of sodium silicate to disperse the slurry. In the second set, suspensions were prepared under the similar conditions by using calcium hydroxide at the same concentrations with sodium carbonate. Sodium silicate was also added to the system as dispersing agent. The solid loading was adjusted at 65 wt.\%. The composition of the slurry used in both set of experiments, is shown in Table 2.

\subsection{Method}

For the slurry preparation powders and distilled water was mixed for $30 \mathrm{~min}$ by a mechanical stirrer (IKA, at speed 3). Either sodium carbonate solution or calcium hydroxide solution (0.06-0.085 wt.\%) was added to the mixture. Then the slurry was poured in a porcelain mill with alumina balls $(1.5 \mathrm{~cm}$ diameter $)$ and milled for $16 \mathrm{~h}$ at $115 \mathrm{rpm}$ (85\% of the critical speed). The density of the slurry was thereafter adjusted to $1800 \mathrm{~g} / 1$ and to $\mathrm{pH} 8-9$. Particle size was determined by sieve analysis, which indicates that $97.5 \%$ of the particles in the slip were below $45 \mu \mathrm{m}$.

To obtain better dispersion sodium silicate solution was gradually added to the slurry prior to mixing. To investigate the optimum amount of sodium silicate

Table 1

Chemical analysis of the raw materials

\begin{tabular}{|c|c|c|c|c|c|c|c|c|c|c|}
\hline Materials & $\mathrm{SiO}_{2}$ & $\mathrm{Al}_{2} \mathrm{O}_{3}$ & $\mathrm{Fe}_{2} \mathrm{O}_{3}$ & $\mathrm{TiO}_{2}$ & $\mathrm{CaO}$ & $\mathrm{MgO}$ & $\mathrm{Na}_{2} \mathrm{O}$ & $\mathrm{K}_{2} \mathrm{O}$ & $\mathrm{SO}_{3}$ & LO.I \\
\hline Clay & 55.0 & 27.5 & 1.5 & 1.5 & 0.3 & 0.5 & 1.0 & 2.5 & 0.5 & 10.0 \\
\hline Kaolin & 52.0 & 32.0 & 1.0 & 0.3 & 0.5 & 0.5 & 0.5 & 1.5 & 0.5 & 10.5 \\
\hline Feldspar & 72.0 & 16.5 & 0.15 & 0.5 & 0.7 & 0.8 & 8.5 & 0.5 & - & 1.0 \\
\hline
\end{tabular}


Table 2

The composition of the slurry

\begin{tabular}{ll}
\hline Material & wt. $\%$ \\
\hline Feldspar & 24 \\
Quartz & 24 \\
Kaolin & 35 \\
Ball clay & 17 \\
\hline
\end{tabular}

that should be added to the system viscosity measurements were performed by using a Brookfield RV II viscometer at $600 \mathrm{rpm}$ (spindle number 3). A Gallencamp torsion viscometer was also used for measuring the viscosity and thixotropy of the suspensions before casting into the mould. The torsion type viscometer contains a horizontal disc suspended by a long wire that is immersed into the slip and spun through an angle of $360^{\circ}$.

The prepared slip was casted into plaster of Paris molds at room temperature and the temperature of the slurry was fixed at $25{ }^{\circ} \mathrm{C}$ during the casting process. After casting for a predetermined time, the excess slip was poured away from the mould and cake thickness data was collected in 5, 10, 20, 40 and $60 \mathrm{~min}$ intervals. Test specimens were then removed form the mould and allowed to dry at $40{ }^{\circ} \mathrm{C}$ for $24 \mathrm{~h}$. The green bodies were sintered at $1250{ }^{\circ} \mathrm{C}$ in an industrial scale kiln (Riedhammer, $65 \mathrm{~m}$ length). A flow diagram of the processing steps is shown in Fig. 1.

Physical properties of the test specimens such as shrinkage, bending strength and water absorption were investigated in green state and after sintering. Shrinkage was measured by a dilatometer (Netch, Germany) and also calculated by measuring the dimensions of the ceramic bars before and after sintering.

Bending strength of the bar shape test specimens $(150 \times 25 \times 12 \mathrm{~mm})$ were measured by applying a 40 $\mathrm{N}$ load to the cross sectional area using a mechanical test equipment.

A water absorption test was accomplished in order to determine the water absorption capacity. In this test the samples were submerged in water for $24 \mathrm{~h}$. Then

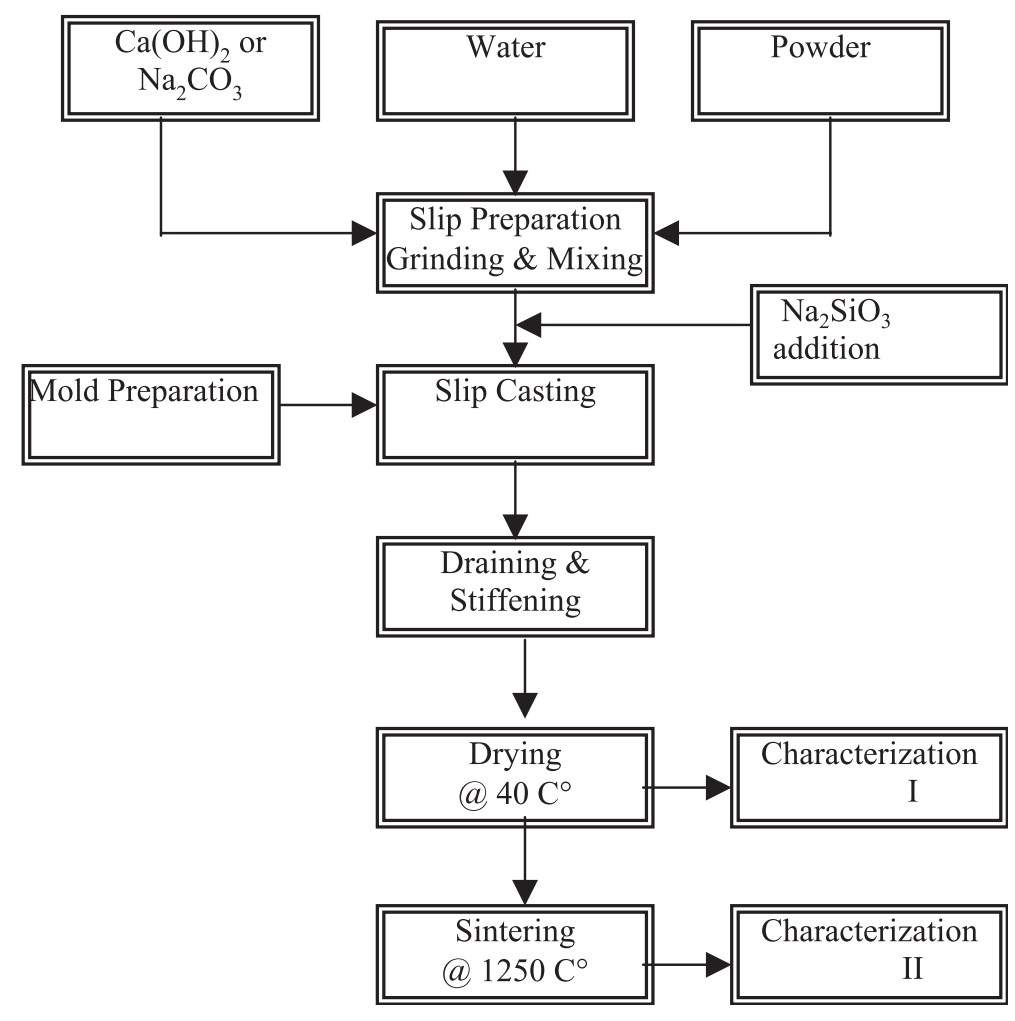

Fig. 1. Flow diagram of the processing steps. 
they were removed from water and weighed. Water absorption of each sample was calculated according to the following formula:

Water Absorption $\%=100\left(W_{\mathrm{s}}-W_{\mathrm{d}}\right) / W_{\mathrm{d}}$

where, $W_{\mathrm{d}}$ is the dry weight of the specimen; $W_{\mathrm{s}}$ is the saturated weight of the specimen.

\section{Results and discussion}

\subsection{Viscosity measurements}

The optimum electrolyte amounts required to disperse the particles in the slip were determined by

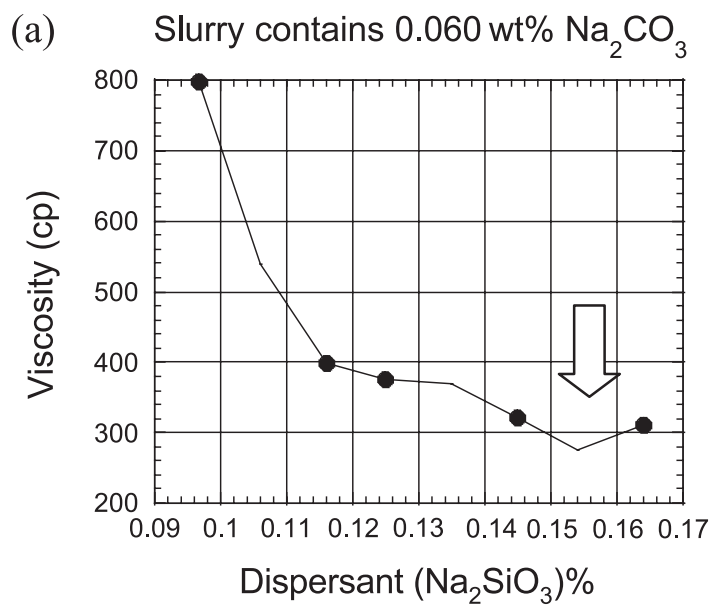

(b) Slurry contains $0.080 \mathrm{wt} \% \mathrm{Na}_{2} \mathrm{CO}_{3}$

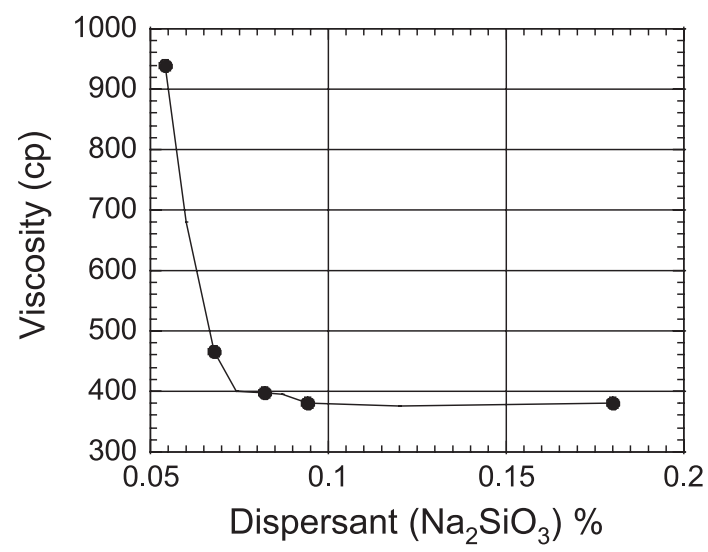

Fig. 2. Optimum electrolyte amount graph for suspension containing $\mathrm{Na}_{2} \mathrm{CO}_{3}$; (a) $0.060 \%$, (b) $0.080 \%$.

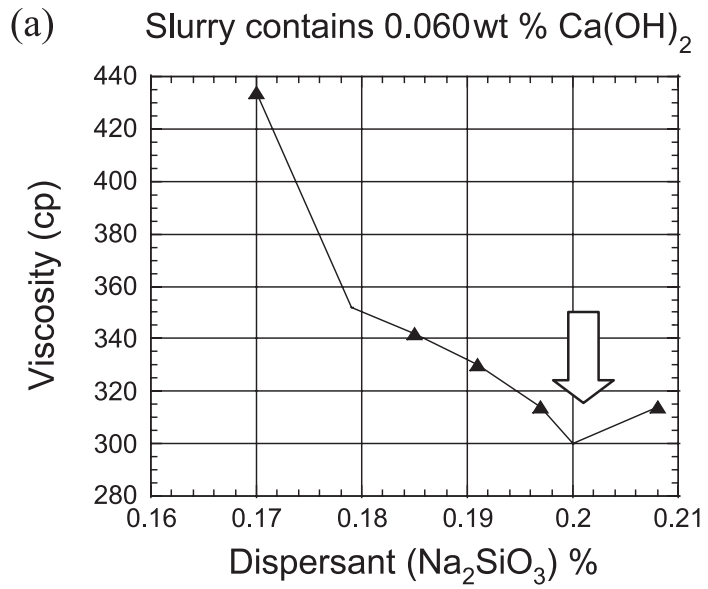

(b) Slurry contains $0.080 w t \% \mathrm{Ca}(\mathrm{OH})_{2}$

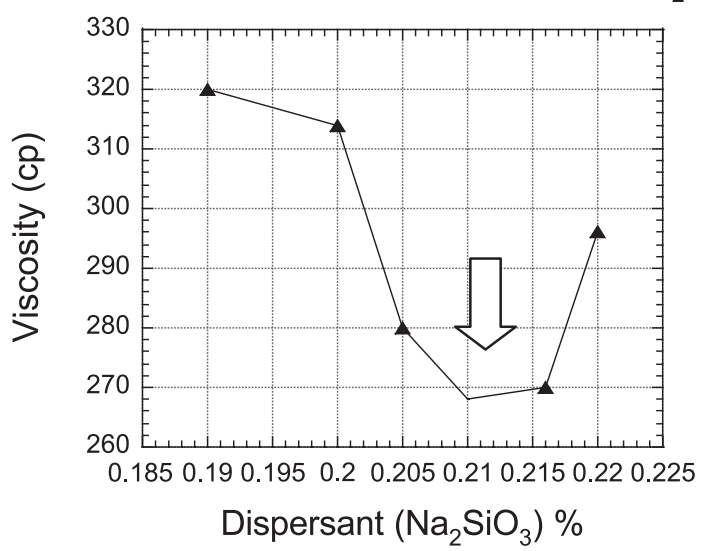

Fig. 3. Optimum electrolyte amount graph for suspension containing $\mathrm{Ca}(\mathrm{OH})_{2}$; (a) $0.060 \%$, (b) $0.080 \%$.

means of viscosity measurements. Fig. 2 shows the optimum amount of sodium silicate that should be added to the slip containing sodium carbonate. It was found that the slip already containing $0.06 \mathrm{wt} . \%$ sodium carbonate exhibited its lowest viscosity $(300$ $\mathrm{cp)}$ at a sodium silicate concentration of $0.154 \%$. Above this concentration, addition of sodium silicate caused an increase in the viscosity. Therefore, it is possible to conclude that at high concentrations of sodium silicate agglomeration starts due to an excess amount of electrolyte. In the presence of $0.09 \%$ sodium silicate viscosity of the slurry is about $800 \mathrm{cp}$.

Similarly Fig. 3 demonstrates the optimum amount of sodium silicate that should be added to the suspension containing calcium hydroxide. The viscosity 
Table 3

Results of the experiments that were carried out by using sodium carbonate

\begin{tabular}{|c|c|c|c|c|c|}
\hline Experiment Number & 1 & 2 & 3 & 4 & 5 \\
\hline $\mathrm{Na}_{2} \mathrm{CO}_{3}(\%)$ & 0.060 & 0.070 & 0.075 & 0.080 & 0.085 \\
\hline $\mathrm{Na}_{2} \mathrm{SiO}_{3}(\%)$ & 0.164 & 0.141 & 0.143 & 0.145 & 0.160 \\
\hline Density $(g / l)$ & 1798 & 1802 & 1800 & 1802 & 1800 \\
\hline 1st viscosity ${ }^{\mathrm{a}}\left({ }^{\circ}\right)$ & 340 & 340 & 337 & 335 & 342 \\
\hline 2nd viscosity ${ }^{\mathrm{a}}\left(^{\circ}\right)$ & 310 & 308 & 304 & 302 & 312 \\
\hline Thixotropy ${ }^{\mathrm{b}}$ & 30 & 32 & 33 & 33 & 30 \\
\hline Temperature $\left({ }^{\circ} \mathrm{C}\right)$ & 25 & 26 & 26 & 25 & 24 \\
\hline Shrinkage (\%)-Green & 1.60 & 2.10 & 1.33 & 1.95 & 1.28 \\
\hline Shrinkage (\%)-Sintered & 7.97 & 7.20 & 7.05 & 8.45 & 7.53 \\
\hline Total Shrinkage (\%) & 9.57 & 9.30 & 8.38 & 10.6 & 9.65 \\
\hline Strength $\left(\mathrm{kg} / \mathrm{cm}^{2}\right)$-Green & 25.11 & 26.87 & 26.28 & 26.95 & 27.43 \\
\hline Strength $\left(\mathrm{kg} / \mathrm{cm}^{2}\right)-$ Sintered & 342.67 & 351.14 & 457.8 & 484.9 & 490.62 \\
\hline Water absorption (\%) & 2.3 & 1.91 & 0.84 & 0.78 & 0.75 \\
\hline
\end{tabular}

${ }^{\mathrm{a}}$ Values obtained by using Torsion type viscometer.

${ }^{\mathrm{b}}$ Thixotropy $=1$ st viscosity -2 nd viscosity.

minimum is at $250 \mathrm{cp}$. There is a big difference between the viscosity values of the suspensions in the absence of sodium silicate containing only calcium hydroxide and sodium carbonate in the beginning.

\subsection{Slip casting related properties}

The physical properties of the green and sintered test specimens and the properties of the slip before the casting process are summarized in Tables 3 and 4 for the $\mathrm{Na}_{2} \mathrm{CO}_{3}$ and $\mathrm{Ca}(\mathrm{OH})_{2}$ systems, respectively.

Viscosity values shown in Tables 3 and 4 were obtained by using the Gallencamp torsion viscometer. The term "second viscosity" was attributed to the value that had been taken after a rest period $(30 \mathrm{~min})$ by keeping the slurry undisturbed. Thixotropy coefficients of the both systems were determined as $30-$ 33 in both sets by getting the difference between the first and second viscosity values. These results suggest a high state of dispersion for the slip.

The thickness of the cast layer for similar suspensions but with different dispersants was determined by the packing of the particles in the layer, which in turn determines the permeability of the layer. The cast layer thickness of the slurries with casting time prepared by using sodium carbonate and calcium hydroxide is illustrated in Figs. 4 and 5, respectively. According to the results calcium hydroxide has a

Table 4

Results of the experiments that were carried out by using calcium hydroxide

\begin{tabular}{|c|c|c|c|c|c|}
\hline Experiment Number & 6 & 7 & 8 & 9 & 10 \\
\hline $\mathrm{Ca}(\mathrm{OH})_{2}(\%)$ & 0.060 & 0.070 & 0.075 & 0.080 & 0.085 \\
\hline $\mathrm{Na}_{2} \mathrm{SiO}_{3}(\%)$ & 0.22 & 0.23 & 0.21 & 0.20 & 0.21 \\
\hline Density $(g / 1)$ & 1800 & 1799 & 1802 & 1796 & 1802 \\
\hline 1st viscosity ${ }^{\mathrm{a}}\left({ }^{\circ}\right)$ & 339 & 342 & 341 & 344 & 320 \\
\hline 2nd viscosity ${ }^{\mathrm{a}}\left({ }^{\circ}\right)$ & 309 & 310 & 309 & 311 & 290 \\
\hline Thixotropy ${ }^{\mathrm{b}}$ & 30 & 32 & 32 & 33 & 30 \\
\hline Temperature $\left({ }^{\circ} \mathrm{C}\right)$ & 26 & 26 & 25 & 24 & 25 \\
\hline Shrinkage (\%)-Green & 1.45 & 1.58 & 1.15 & 2.03 & 1.85 \\
\hline Shrinkage (\%)-Sintered & 8.35 & 8.49 & 6.61 & 8.22 & 7.98 \\
\hline Total shrinkage $(\%)$ & 9.8 & 10.07 & 7.76 & 10.25 & 9.83 \\
\hline Strength $\left(\mathrm{kg} / \mathrm{cm}^{2}\right)$-Green & 25.34 & 25.91 & 29.16 & 35.8 & 37.94 \\
\hline Strength $\left(\mathrm{kg} / \mathrm{cm}^{2}\right)$-Sintered & 496.8 & 524.26 & 544.36 & 658.3 & 650.52 \\
\hline Water Absorption (\%) & 0.74 & 0.71 & 0.70 & 0.68 & 0.69 \\
\hline
\end{tabular}

\footnotetext{
${ }^{a}$ Values obtained by using Torsion type viscometer.
}

${ }^{\mathrm{b}}$ Thixotropy $=1$ st viscosity -2 nd viscosity. 


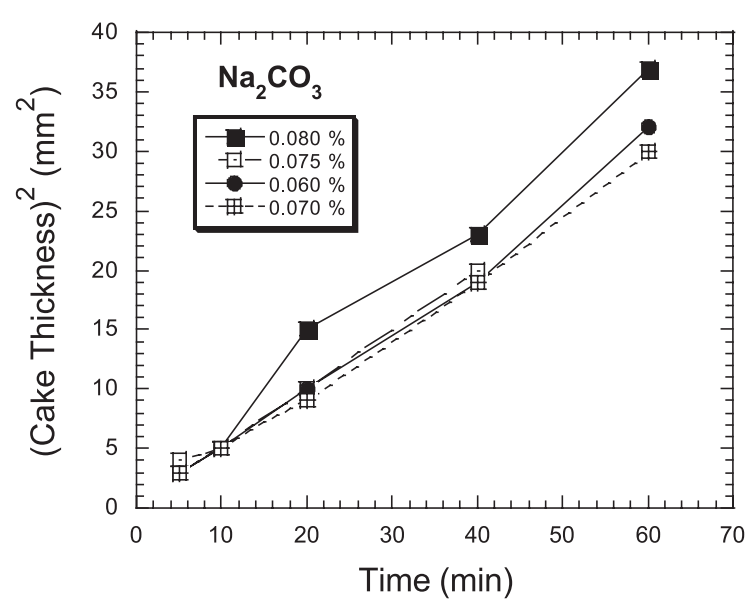

Fig. 4. Cake thickness values of the slip containing sodium carbonate at different concentrations with casting time.

positive effect on the casting rate of the ceramic slips. In the case of sodium carbonate the slope of the graph is 0.68 in Fig. 4, and the maximum cake thickness is $6.08 \mathrm{~mm}$ after $60 \mathrm{~min}$ drying time and with $0.08 \%$ sodium carbonate content. On the other hand for samples with calcium hydroxide $(0.080 \%)$ the slope reaches 0.79 . The cake thickness is $7.2 \mathrm{~mm}$ after 60 min drying period.

For a dispersed suspension, the particles will be densely packed in the cast layer and there will be a limited secondary arrangement of the particles after they have landed on the cast layer surface. However, when the suspension is weakly flocculated, clusters of particles exist in the suspension. Therefore, the cast layer will have a greater degree of porosity (Zhang and Binner, 2002).

Bending strength of the sintered products containing calcium hydroxide was higher than the samples prepared by sodium carbonate. Higher strength values may be attributed to better homogenization during slip preparation.

Water absorption test results showed that the specimens which have a higher bending strength indicates a lower water absorption capacity. Therefore minimum absorption values were obtained in the specimen prepared by using $0.080 \% \mathrm{Ca}(\mathrm{OH})_{2}$.

Results of the study shows that $\mathrm{Ca}(\mathrm{OH})_{2}$ might serve the deflocculation process yielding a better casting rate to the system through similar mechanisms as seen for sodium compounds such as $\mathrm{Na}(\mathrm{OH}), \mathrm{Na}_{2} \mathrm{CO}_{3}$.
The effects of sodium carbonate and sodium silicate are different in slip preparation. Sodium carbonate hydrolyses during the process to yield sodium hydroxide and carbonic acid. On the other hand sodium silicate gives free alkaline ions and silicic acid after hydrolysis. The resultant silicic acid prevents the flocculation of the slip. The ball clay in the slip casting contains some organic substances such as humic acids. By addition of the sodium carbonate into the slip an alkaline region is obtained. The alkaline ions help this structure become colloidal, reacting with the organic substances in the slip when sodium silicate is added. As a result of precipitation of the anions of the alkaline salts in the slip the clay particles, which form the slip, become colloidal.

Ching et al. (1994) investigated the slip rheology by the presence of calcium hydroxide. The sulphates may accompany the ball clay or calcium sulphate may be added to achieve desired rheology. The sulphate can also contribute to glaze defects and adds sulphur oxide emissions from the kiln. According to their study, calcium slips can increase the casting rate by as much as $65 \%$ and calcium hydroxide might serve the same function with calcium sulphate and, at the same time, eliminate the undesirable characteristics of the sulphate anions.

Results of this current work are in good agreement with those observed in the previous work carried out by Ching et al. (1994).

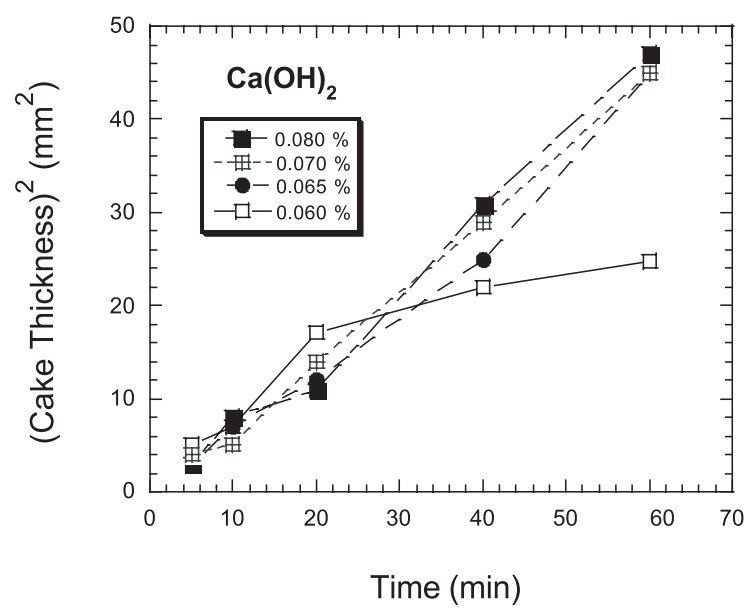

Fig. 5. Cake thickness values of the slip containing calcium hydroxide at different concentrations with casting time. 


\section{Conclusions}

Results of this study indicated that the use of calcium hydroxide might cause significant improvements in the casting behaviour of the slips. It has also some positive effects on physical properties of the green and sintered bodies.

- The use of calcium hydroxide followed by addition of sodium silicate lowered the viscosity of the slips. Higher viscosity values were obtained by using sodium carbonate.

- The use of calcium hydroxide at 0.080 wt.\% caused an increase in the cake thickness by as much as $30 \%$ within 60 min. Calcium hydroxide accelerated the consolidation.

- The dry and sintered strength of the final products obtained by casting of the slips containing calcium hydroxide was higher than the products containing sodium carbonate.

- Water absorption percentages of the specimens containing calcium hydroxide were lower than the specimens that contained sodium carbonate.

- The addition of calcium hydroxide instead of sodium carbonate required much higher amounts of sodium silicate to deflocculate to similar viscosity levels.

\section{Acknowledgements}

The authors are grateful to Dr. Ender Balci for his valuable contributions and to Serel Seramik, Turkey who kindly supplied raw materials and supported this work.

\section{References}

Ching, H., Mancini, K., Gilbert, R., 1994. Improved casting slip properties. Am. Ceram. Soc. Bull. 73, 70-74.

Corradi, A., Manfredini, T., Pellacani, G., Pozzi, P., 1994. Deflocculation of concentrated aqueous clay suspensions with sodium polymethacrylates. J. Am. Ceram. Soc. 77, 509-513.

Everest, D.H., 1988. Basic Principles of Colloidal Science. Royal Society of Chemistry, London.

Guler, C., Balci, E., 1998. Effect of some salts on the viscosity of slip casting. Appl. Clay Sci. 13, 213-218.

Luckham, P.F., Rossi, S., 1999. The colloidal and rheological properties of bentonite suspensions. Adv. Colloid Interface Sci. 82, $43-92$.

Mutsuddy, B.C., 1994. Rheology and mixing of ceramic mixtures used in plastic molding. In: Lee, B.I., Pope, E.A. (Eds.), Chemical Processing of Ceramics, vol. 8. Marcel Dekker, New York.

Papo, A., Piani, L., Ricceri, R., 2002. Sodium tripolyphosphate and polyphosphate as dispersing agents for kaolin suspensions: rheological characterization. Colloids Surf., A Physicochem. Eng. Asp. 201, 219-230.

Reed, J.S., 1995. Principles of Ceramic Processing, 2nd ed. Wiley, Canada.

Rosen, J.M., 1989. Surfactants and Interfacial Phenomena, 2nd ed. Wiley, Canada.

Shan, Y., 1990. The international training course on ceramic production technology. Lecture notes 2. Tangshan, The People's Rep. of China.

Williams, R.A., 1992. Colloid and Surface Engineering: Applications in the Process Industries. Butterworth-Heinemann, Oxford.

Zhang, Y., Binner, J., 2002. Enhanced casting rate by dynamic heating during slip casting. J. Eur. Ceram. Soc. 22, 135-142. 